\title{
Does General Anesthesia and Extended Prostate Biopsies Enhance Prostate Cancer Detection Rate?
}

\author{
Paulo Rodrigues*, Flavio Hering, Eli Cielici and Joao Carlos \\ Campagnari \\ Urology Clinic, Hospital Beneficência Portuguesa of São Paulo, Brazil
}

\section{Research Article \\ Volume 3 Issue 2}

Received Date: March 12, 2018

Published Date: April 24, 2018

*Corresponding author: Paulo Rodrigues, MD, Urology Clinic, Hospital Beneficência Portuguesa of São Paulo -São Paulo, Rua Teixeira da Silva 34 -10 andar, São Paulo, Brazil, CEP - 04002-030, Tel/Fax: +55 113266 6455; Email: paulortrodrigues@uol.com.br

\section{Abstract}

Objectives: Negative prostate biopsies results in extra-expenditures. We explored if prostate biopsies done under general anesthesia may facilitate higher number of samples and better gland evaluation with better sampling and targeting.

Methods: 2,168 prostate biopsies (mean age: 59.2, SD:3.0) with at least 18 fragments undertaken under general anesthesia were studied. Narrow Prostate Specific Antigen (PSA) stratification, gland volume and number of fragments were analyzed according to presence of nodes and vascularity as for prostate cancer (CaP). $p$ values were significant if $<0.05$.

Results: Overall, CaP detection rate was $35.8 \%$. Patients showed the same diagnostic rate on 1 st $(35.7 \%), 2^{\text {nd }}(33.9 \%), 3^{\text {rd }}$ $(35.7 \%)-p>0.05$; with diminished probability for the $4^{\text {th }}(18.2 \%)$ biopsy- $p>0.05$.

PSA < 4.0 showed similar rate of CaP detection - 32.4\% X 35.6\%; and number of CaP (+) cores - 3.9 X 4.6; in comparison to those with higher PSA.

Suspected node on US increased the rate of CaP diagnosis $(p=0.001)$ but node was not specific for CaP. Vascularity of the node was not related to CaP detection. PSA $>4.0$ is more relevant for low volume gland than for larger glands.

Conclusions: Contrary to expectation use of general anesthesia did not improve the diagnostic detection rate for $\mathrm{CaP}$ on different sessions of biopsies except for small gland with PSA $<4 \mathrm{ng} / \mathrm{dl}$ where the detection rate improved with statistical significance.

Keywords: Prostate Cancer; Prostate biopsy; Ultrasonography; Prostate gland and Analgesia 


\section{Introduction}

Although PSA is a potent indicator when to perform the biopsy, the via, number of fragments and even the PSA level leading to the decision to biopsy is a matter of debate. Analgesia may potentially influence the quality of the sampling because pain may rush the examiner and limit the number of procured cores.

Transrectal ultrasound (TRUSG) became the most popularized way to perform prostate biopsy allowing direct morphological examination of the gland such as nodules and hypervascularized areas. Identification of potential areas of interest to be sampled demands time and expertise from the examiner in order to increase the number of cores [1-3] avoiding the dilemma of repeating the procedure in the future.

The old concept of 6-core sampling was based on empirical experience and underperforms in diagnosing prostate cancer [4] when compared to any schemes with more samples $[1,2,5]$. Four forces in contemporary series seem to play against sextant pattern: (1) CaP diagnosis has been shift toward less voluminous disease under the spread use of PSA lessening the chance of appropriate sampling of malignant tissue, (2) prostate biopsy represents a tiny sample of the gland - 0.04\% [6] (3) organ-confined disease presents better biochemical recurrent free-survival driving the tendency to lower the PSA value as an indication to biopsy [7] at the same time there is acknowledgement that the (4) higher number of cores may improve the diagnostic rates. We assumed that doing prostate biopsy under general anesthesia would enhance the diagnostic rate of $\mathrm{CaP}$ and improve the sampling of desired areas.

\section{Methods}

2,168 consecutive men (mean age: 59.2, SD:3.0) submitted to prostate biopsy were prospectively studied during 2008 to 2012 after consenting for the study and signing for it. 1,896 patients had had his first biopsy, 168 his second biopsy, 56 his third, 44 his fourth and 4 cases had had his fifth biopsy.

Patients were requested to have prostate biopsy due to clinical suspicion of prostate cancer on digital rectal examination (DRE) - 87 cases (4\%) or elevation of PSA (96\%) - primary elevation, persistent elevation or ascending pattern of elevation [8].
Patients received prophylactic fluoroquinolone for 5 days after the procedure. Additional antibiotics were added for those considered at risk for endocarditis or with implanted prosthetic devices. Patients received a fleet enema on admission to the outpatient surgical unit. All saturation biopsies were performed in the operating room with anesthesia support through transrectal-guided prostate biopsy under intravenous general anesthesia with propofol. The prostate gland was imaged with the Acuson 128XP ultrasound machine (Acuson Computed Sonography, Mountain View, California) with an EC7 5 to $7 \mathrm{MHz}$ endocavity 45-degree probe enabling proper visualization of the needle and the intended area.

After inventorying the prostate and evaluating suspicious lesions, Doppler evaluation was conducted for the presence of hyper or hypovascularized areas and echogenic characteristic of the eventually visualized nodular formation. Saturation biopsy was performed using the automatic Max Core Disposable 18 gauge MC1820 Biopty gun (C. R. Bard, Inc., Covington, Georgia).

In our biopsy strategy we obtained the first cores at the most lateral border at the base and extended them up to the border to include the mid and apical zones of the prostate. Biopsy was next directed slightly medial by rotating the probe 20 to 30 degrees axially from the outermost row and so on until the midline of the prostate was reached. This biopsy method ensured complete sampling of the whole prostate gland irrespective of size. If present, at least 3 samples from hypoechoic or hypervascularized lesions were also performed. The transition zone was biopsied selectively by introducing the needle mid prostate to the interface of the peripheral and transition zones in the midline.

The number of sample cores was no less than 18 and sampled according to radiological criteria on the presence of nodes, hypoechogenic areas or hypervascularized areas, as the simultaneous Doppler was done. The relationship between PSA and the probability of $\mathrm{CaP}$ diagnosis were analyzed for each stratification of 1.0 $\mathrm{ng} / \mathrm{ml}$ of PSA starting from $2.0 \mathrm{ng} / \mathrm{ml}$ and with larger interval until 20.

PSA at saturation biopsy was also evaluated as a continuous variable using categories of $\langle 4.0\rangle 4.0,$,4 to 10,10 to $<20$ and $>20 \mathrm{ng} / \mathrm{ml}$. Associations were evaluated based on the chi-square test for nominal variables and the Wilcoxon's rank sum test for continuous 
variables, such as PSA, number of $\mathrm{CaP}$ cores and number of saturation cores. The association of each nominal variable with a $\mathrm{CaP}$ diagnosis was calculated with $95 \%$ confidence interval. All calculated $p$ values were 2 -sided and $\mathrm{p}<0.05$ was considered statistically significant. IBMSPSS software was used.

Different prostate volume intervals ( $<20 \mathrm{~g}$; 21 to $40 \mathrm{~g}$;; 41 to $60 \mathrm{~g} ; 61$ to $80 \mathrm{~g} ; 81$ to $100 \mathrm{~g}$ and $>100 \mathrm{~g}$ ), PSA, number of $(+)$ cores and $\mathrm{CaP}$ detection rate were all also analyzed. The study was approved by Institutional Review Board of the involved hospitals which dispensed a protocol as the exam is part of the regular exams for CaP.

\section{Results}

Amongst the studied population 775 (35.8\%) of 2,168 cases were diagnosed with CaP. Patients had a maximum of 38 and a minimum of 18 fragments. Non-cancer (median; 19.1 fragments) and the cancer group (median: 18.8 fragments - $p>0.05$ ) had comparable amount of fragments procured. Except for the PSA interval 9.1-10 where the number of fragments were higher (mean: 27.5) the number of fragments remained stable (mean: 18.1) for the whole population. Patients showed the same probability of $\mathrm{CaP}$ diagnosis on biopsy despite they have had it as the first $(36.2 \%), 2$ biopsies $(33.9 \%)$ or 3 biopsies $(35.7 \%)$ ( $p>0.05)$ with significant reduction of prostate cancer diagnosis after 4 biopsies (18.2\%) (p < 0.05 ). A low number of patients with 5 biopsies did not allow comparative analysis. Analysis of the prevalence of prostate cancer diagnosis stratified by narrowed PSA intervals showed difference on the range of cancer detection in the 3.1 to 6.0 interval and $15.1-17.0$ - Table 1.

\begin{tabular}{|c|c|c|c|c|c|}
\hline PSA & $\begin{array}{c}\text { Number of biopsied } \\
\text { cases in this PSA } \\
\text { interval }\end{array}$ & $\begin{array}{c}\text { \% of CaP } \\
\text { diagnosed in this } \\
\text { PSA range }\end{array}$ & $\begin{array}{c}\text { \% of the total cases } \\
\text { (775) with CaP (n) }\end{array}$ & $\begin{array}{c}\text { \% of the total cases } \\
\text { (1393) with non- } \\
\text { malignant finding (n) }\end{array}$ & p \\
\hline$<2,0$ & 85 & $24.70 \%$ & $2.7 \%(21)$ & $2.9 \%(64)$ & 0.083 \\
\hline $2,0-3,0$ & 136 & $32.30 \%$ & $5.6 \%(44)$ & $4.2 \%(92)$ & 0.06 \\
\hline $3,1-4,0$ & 353 & $34.20 \%$ & $15.6 \%(121)$ & $10.7 \%(232)$ & 0.048 \\
\hline $4,1-5,0$ & 402 & $36.30 \%$ & $18.8 \%(146)$ & $11.8 \%(256)$ & 0.045 \\
\hline $5,1-6,0$ & 327 & $38.80 \%$ & $16.3 \%(127)$ & $9.2 \%(200)$ & 0.045 \\
\hline $6,1-7,0$ & 255 & $30.10 \%$ & $9.9 \%(77)$ & $8.2(178)$ & 0.08 \\
\hline $7,1-8,0$ & 124 & $22.50 \%$ & $3.6 \%(28)$ & $4.4 \%(96)$ & 0.075 \\
\hline $8,0-9,0$ & 72 & $40.20 \%$ & $3.7 \%(29)$ & $2.0 \%(43)$ & 0.055 \\
\hline $9,1-10,0$ & 102 & $35.20 \%$ & $4.6 \%(36)$ & $3.0 \%(66)$ & 0.06 \\
\hline $10,0-12,0$ & 101 & $38.60 \%$ & $5.0 \%(39)$ & $2.8 \%(62)$ & 0.05 \\
\hline $12,1-15,0$ & 73 & $30.10 \%$ & $2.8 \%(22)$ & $2.3 \%(51)$ & 0.068 \\
\hline $15,1-17,0$ & 23 & $65.20 \%$ & $1.9 \%(15)$ & $0.4 \%(8)$ & 0.03 \\
\hline $17,1-20,0$ & 48 & $54.20 \%$ & $3.3 \%(26)$ & $1.0 \%(22)$ & 0.05 \\
\hline$>20,1$ & 67 & $65.70 \%$ & $5.6 \%(44)$ & $1.0 \%(23)$ & 0.04 \\
\hline Total & 2168 & & 775 & 1393 & \\
\hline
\end{tabular}

Table 1: Comparison of prostate cancer diagnostic rate on the studied population separated by PSA intervals.

PSA- Prostate Specific Antigen

CaP- Prostate cancer cases

Our data showed that $574(26.4 \%)$ out of 2168 cases presented in the PSA range $<4.0 \mathrm{ng} / \mathrm{ml}$ and they would not have been biopsied if that limit were the adopted cutoff. In that range the amount of diagnostic of CaP was $32.4 \%$ (186 out of 574 cases) very similar to the amount rate of $\mathrm{CaP}$ in higher limit ranges - mean: $35.6 \%(\mathrm{p}<0.05)$ - PSA: 4.1 to < 20.0; meaning that PSA were not discriminatory when a large amount of samples were procured from the prostate.

In the same way, the number of $(+)$ biopsied cores remained constant along all PSA breakdowns with an median of 4.5 positive cores among 18.8 procured fragments - Table 2 . 


\begin{tabular}{|c|c|c|c|c|}
\hline PSA & $\begin{array}{c}\text { Number of } \\
\text { cases }\end{array}$ & $\begin{array}{c}\text { Mean number of } \\
\text { biopsied cores }\end{array}$ & $\begin{array}{c}\text { Mean number of positive } \\
\text { biopsied cores }\end{array}$ & $\begin{array}{c}\text { \% of cores with neoplasic findings from } \\
\text { the total biopsied cores }\end{array}$ \\
\hline$<2,0$ & 21 & 18.8 & 3.2 & $17.10 \%$ \\
\hline $2,0-3,0$ & 44 & 20.1 & 5,1 & $25.20 \%$ \\
\hline $3,1-4,0$ & 121 & 17.9 & 3,5 & $19.80 \%$ \\
\hline $4,1-5,0$ & 146 & 21.2 & 4.5 & $31.30 \%$ \\
\hline $5,1-6,0$ & 127 & 17.5 & 5.5 & $26.10 \%$ \\
\hline $6,1-7,0$ & 77 & 19.2 & 5 & $24.20 \%$ \\
\hline $7,1-8,0$ & 28 & 17.9 & 4.3 & $9.40 \%$ \\
\hline $8,0-9,0$ & 29 & 18.6 & 1.8 & $10.20 \%$ \\
\hline $9,1-10,0$ & 36 & 27.8 & 2.9 & $31.50 \%$ \\
\hline $10,1-12,0$ & 39 & 17.9 & 5.6 & $37.90 \%$ \\
\hline $12,1-15,0$ & 22 & 20.1 & 2 & $31.20 \%$ \\
\hline $15,1-17,0$ & 15 & 16.2 & 6 & $54.20 \%$ \\
\hline $17,1-20,0$ & 26 & 16 & 5 & $\mathbf{2 4 . 9 0 \%}$ \\
\hline$>20,1$ & 44 & 15.3 & 8.3 & $\mathbf{4 . 4 8}$ \\
\hline $\begin{array}{c}\text { Total } \\
\text { average }\end{array}$ & $\mathbf{1 8 . 8}$ & & \\
\hline
\end{tabular}

Table 2: Relationship between the number of cores procured and percent CaP cores according to different PSA breakdowns.

The number of $(+)$ cores for CaP stratified by PSA range did not differ according to PSA breakdowns. Except for the PSA > 20 where the number of positive cores were higher (8.3) the average number of $\mathrm{CaP}$ cores remained stable at 4.5 positive cores from an average of 18.8 biopsied cores in the CaP cases. Even for those cases with PSA $<4.0 \mathrm{ng} / \mathrm{ml}$ the number of positive cores averaged 3.9 for an averaged 18.9 procured cores in comparison to the PSA $>4.0 \mathrm{ng} / \mathrm{ml}$ where positive cores accounted 4.6 in average in 18.9 sampled cores ( $p>0.05)$.

$890(41.1 \%)$ of 2168 cases had nodular lesions visualized during trans-rectal evaluation. 521 of 890
(58.5\%) cases with nodular lesions on US were diagnosed with CaP while 254 of 1278 (19.8\%) without nodular US findings showed $\mathrm{CaP}$ diagnosis $(\mathrm{p}=0.001)$. This meant that $(+)$ finding on US enhances the chance of $\mathrm{CaP}$ on prostate biopsy. However, when the subset of $\mathrm{CaP}$ cases where analyzed by laterality of the suspected lesion on US it was not related to the side of CaP localization, as 251 of $521(48.2 \%)$ cases were diagnosed on the same side of the suspected lesion and 270 of 521 (51.8\%) cases had $\mathrm{CaP}$ diagnosed on the contra-lateral side of the suspected lesion with no significant difference by the laterality $(\mathrm{p}=$ 0.2 ) - Table 3.

\begin{tabular}{|c|c|c|c|}
\hline & US (+) - same side & US (+) - contralateral side & US (-) \\
\hline $\mathrm{CaP}(+)(775)$ & $56 \%(251)$ & $61.1 \%(270)$ & $19.8 \%(254)$ \\
\hline $\mathrm{CaP}(-)(1393)$ & $43.9 \%(197)$ & $38.9 \%(172)$ & $80.1 \%(1024)$ \\
\hline
\end{tabular}

Table 3: Relationship between CaP diagnosis, US finding of suspected lesion and laterality of the nodular formation.

Moreover, laterality of suspected lesion on US was not different in the group diagnosed with $\mathrm{CaP}$ (251 cases with cancer - right side: 134 cases; left side: 117 cases) or on the non-CaP groups (197 cases without cancer - right side: 104 cases; left side: 93 cases $)(\mathrm{p}=0.4)$ - Figure 1 . 


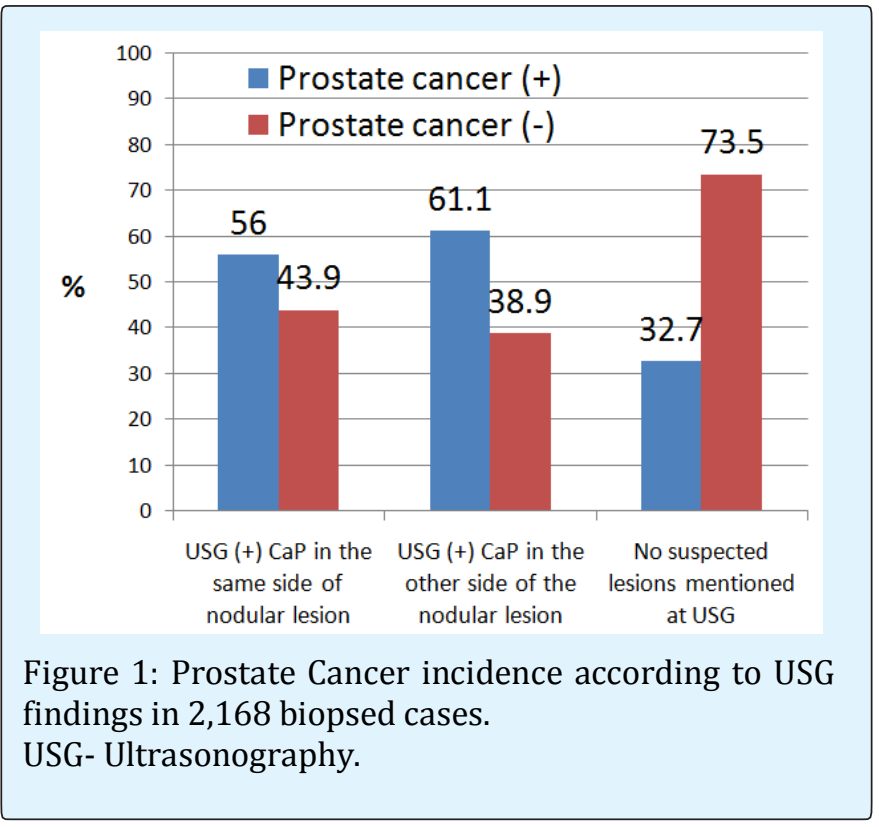

On the other hand, the subset of patients diagnosed with CaP showed an unpredictable pattern on laterality with only $32.8 \%$ of the total cases of diagnosed CaP in the same side of the identified node, with $34.8 \%$ of the cases showing neoplasia in the contra-lateral side of the suspected node and $32.7 \%$ of the neoplasic cases showing no suspected lesion $(\mathrm{p}=0.9)$.

Interestingly, the evaluation of the density of the vascularity of the nodular lesions as detected by Doppler exam during the procedure showed that from 890 detected nodular formations only 195 cases (21.9\%) showed hypervascularity pattern (right - 103; left - 92) with no CaP detected on the hypervascularized lesions in the left side (0 in 92) and in $49 \%$ in the right hypervascularized nodules (51 in 103) ( $\mathrm{p}<0.0001)$.

Prostate volume however, showed a trend to increase PSA accordingly but the CaP diagnostic rate decreased as the volume increased with no differences from the measured PSA for the malignant and non-malignant biopsied cases for prostate volume larger than $21 \mathrm{~g} \mathrm{-}$ Table 4.

\begin{tabular}{|c|c|c|c|c|}
\hline & CaP (n) & Non-CaP & \% of cancer & Total \\
\hline$<20 \mathrm{~g}$ & 49 & 36 & $57.60 \%$ & 85 \\
\hline $21-40 \mathrm{~g}$ & 378 & 538 & $41.30 \%$ & 916 \\
\hline $41-60 \mathrm{~g}$ & 194 & 378 & $33.90 \%$ & 572 \\
\hline $61-80 \mathrm{~g}$ & 67 & 259 & $20.50 \%$ & 326 \\
\hline $81-100 \mathrm{~g}$ & 54 & 104 & $34.20 \%$ & 158 \\
\hline$>100 \mathrm{~g}$ & 33 & 78 & $29.70 \%$ & 111 \\
\hline Total & 775 & 1393 & & 2168 \\
\hline
\end{tabular}

Table 4: Percent of prostate cancer diagnosis on prostate biopsy according to the prostate gland volume (g).

As expected, as the mean number of cores were constant the rate of $\mathrm{CaP}$ diagnosis was higher in the lower volumes intervals $(<40 \mathrm{~g})$ when compared to voluminous gland $(>40 \mathrm{~g})(\mathrm{p}<0.03)$ with a trend to diminish the diagnostic rate of $\mathrm{CaP}$ as prostate volume enlarged $(\mathrm{p}<0.004)$.

\begin{tabular}{|c|c|c|c|c|}
\hline & $\begin{array}{c}\text { Median PSA level for the } \\
\text { whole group }\end{array}$ & $\begin{array}{c}\text { Median PSA for CaP } \\
\text { patients }\end{array}$ & $\begin{array}{c}\text { Median PSA for non- } \\
\text { malignant patients }\end{array}$ & $\begin{array}{c}\text { CaP X non-Cap } \\
\text { cases }\end{array}$ \\
\hline$<20 \mathrm{~g}$ & 3.5 & 4.2 & 1,91 & $\mathrm{p}<0.05$ \\
\hline $21-40 \mathrm{~g}$ & 4.75 & 4.57 & 4.2 & n.s. \\
\hline $41-60 \mathrm{~g}$ & 6.4 & 7.1 & 6.73 & n.s. \\
\hline $61-80 \mathrm{~g}$ & 7.01 & 8.2 & 7.4 & n.s. \\
\hline $81-100 \mathrm{~g}$ & 6.95 & 7.57 & 8.15 & n.s. \\
\hline$>100 \mathrm{~g}$ & 7.93 & 4.05 & 10.4 & $\mathrm{p}<0.05$ \\
\hline
\end{tabular}

Table 5: Relationship between prostate gland volume $(\mathrm{g})$ and PSA level in the rate of prostate cancer detection rate by TRUSG guided biopsy.

TRUSG- Trans-rectal ultrasonography. 
PSA was determinant for the chance of CaP diagnosis in cases where prostate gland volume is $<20 \mathrm{~g}$. Herein, $\mathrm{CaP}$ cases showed a median PSA: $4.2 \mathrm{ng} / \mathrm{ml}$ whereas the nonCaP showed a median of PSA: 1.91 ( $p<0.05)$. Likewise, prostate gland $>100 \mathrm{~g}$ also showed lesser trend to the diagnosis of CaP if PSA were $<10.0$ ( $p<0.05)$.

\section{Discussion}

The indication to biopsy the prostate gland due to abnormal DRE in our study was $4 \%$ but it is still an absolute indication in the urological community [9]. However, the main reason prostate biopsy is nowadays indicated is the sole elevation of PSA in combination or not with abnormal DRE. It is acknowledged that prostate with PSA between 4 and $10 \mathrm{ng} / \mathrm{ml}$ leads to 20 to $30 \%$ of false-negative $\mathrm{CaP}$ due to inappropriate sampling of the gland [9-11].

It is still not clear where is the best predictor to invasively investigate the prostate for a PSA elevation but it can be claimed that lowering PSA bar will result in higher organ-confined disease detection rate and better cure rates [1] although an undesired effect of over detection cancer may accompany this recommendation. In that particular, our data reveals that $186(32.4 \%)$ of the $\mathrm{CaP}$ cases were diagnosed with PSA $<4.0 \mathrm{ng} / \mathrm{ml}$ which is highly superior to Catalona's series [12,13] and others [1] where $22 \%$ of their series had CaP diagnosis with PSA levels of 2.6 to $4.0 \mathrm{ng} / \mathrm{ml}$ possibly reflecting the higher number of cores and use of anesthesia allowing better sampling.

Our rate was kept higher even in comparison to the 21 cores sampling from Guichard's series done under local anesthesia where the diagnostic rate was only $25 \%$ on those with PSA $<4.0 \mathrm{ng} / \mathrm{ml}$ [3] which seems to be appealing since this sub-group of low PSA represent the more curable cases and more prone to false-negative first biopsy.

As 65 to $90 \%$ of the patients claim discomfort during the procedure, some radiologists may feel pressed to end the exam not targeting desired areas [14]. Good sedation allied to higher number of cores seemed to be superior to sextant [15] and 12-cores [2,14]. Our studied population with a median 18.8 cores/patient revealed a total detection rate of $35.8 \%$ for $\mathrm{CaP}$ which is higher than that in the literature with 20 cores $[3,14]$ possibly because of undisturbed time to examine and sample the gland.
Our data was stratified by narrower intervals of PSA breakdown differentiating it from other studies where the PSA breakdown is analyzed into wider intervals $(<4.0 ; 4-$ $10 ;>10$ and so on). Our routine use of at least 18 fragments did improve the detection rate to $35.8 \%$ but on the specific subgroups with prostate volume $<20 \mathrm{~g}$ and PSA $<4.0$ where the gain on detection rate showed impressive improvement in comparison to the literature [16]. Our findings showed a plateau effect on the 18 cores for PSA > 4 with no gain on the diagnostic rate [1].

Stewart [17] pioneered the excessive number of cores and increased the detection rate to $34 \%$ in patients with previous sextant biopsy similar to our $35.8 \%$ rate. Intuitively, adding more cores to the biopsied gland would enhance the detection rate of $\mathrm{CaP}$ but a plateau effect seemed to be evident at near at 20 procured cores as demonstrated in our study as well as others $[15,18,19]$.

Although many studies did show improvement on detection rate with more cores, the majority of those studies compared sextant to 10 -cores or 12 cores templates in previously biopsied-negative patients [2]. Moreover, as at least 18-fragments were routinely used in our study it did not improve the detection rate on voluminous gland either probably meaning that if $\mathrm{CaP}$ is present a higher number of cores would be necessary in voluminous gland or the alteration in PSA is related to the volume and not to CaP itself.

TRUS initially substituted the digitally oriented approach of areas to be biopsied because US seemed to identify more properly $\mathrm{CaP}$ areas. However, the acknowledgement of non-characteristic echogenic appearance of $\mathrm{CaP}$ led Hodges to adopt empirical sextant approach [4]. As also showed in our data, the identification of nodular formation or vascularity were not related to higher chance of $\mathrm{CaP}$ detection as only $28.2 \%$ of those with (+) finding on US was diagnosed with CaP similar to $19.8 \%$ of those with (-) finding on US showing neoplasia.

It is noteworthy that $34.8 \%$ of $\mathrm{CaP}$ cases were diagnosed on the opposite side of the identified US lesion contradicting the ordinary expectation. Moreover, $67.6 \%$ of the CaP cases did not show any US suspicious lesion on the biopsied area. A more stringent analysis of US findings revealed that diagnosing $\mathrm{CaP}$ based on US lesions corresponded almost to toss a coin. 
Surprisingly, as our patients were under general anesthesia we expected a much higher detection rate for $\mathrm{CaP}$ as higher number of samples and better evaluation of the glandular areas were possible. However, when we looked up to additional parameters that could improve the detection rate such as nodular formation, hypervascularity, prostate volume and PSA, only PSA and volume influenced the chance of detection, meaning that high PSA with low prostate volume enhances the CaP detection rate in 18 cores scenario but not the additional findings obtained by US. Surprisingly, all other combinations of PSA breakdown did not predict higher chance to detect $\mathrm{CaP}$.

In conclusion, doing extended prostate biopsy under general anesthesia with at-least-18 fragments suggests that PSA level was not determinant on the possibility of CaP diagnosis, except for cases with PSA $<4.0 \mathrm{ng} / \mathrm{ml}$ where higher number of cores enhanced the detection rate for CaP. Similarly, (+) findings (nodular formation or hypervascularized areas) on TRUS did not correlate to neoplasic areas.

\section{References}

1. Babaian RJ, Toi A, Kamoi K, Troncoso P, Sweet J, et al. (2000) Comparative analysis of sextant and an extende 11-core multisite directed biopsy strategy. J Urol 163(1): 152-156.

2. Naughton CK, Miller DC, Mager DE, Ornstein DK, Catalona WJ (2000) A prospective randomized trial comparing 6 versus 12 prostate biopsy cores: impact on cancer detection. J Urol 164(2): 388-395.

3. Guichard G, Larré S, Gallina A, Lazar A, Faucon H, et al. (2007) Extended 21-sample needle biopsy protocol for diagnosis of prostate cancer in 1000 consecutive patients. Eur Urol 52(2): 430-435.

4. Hodge KK1, McNeal JE, Terris MK, Stamey TA (1989) Random systematic versus directed ultrasound guided transrectal biopsies of theprostate. J Urol 142(1): 71-76.

5. Stamatiou K, Alevizos A, Karanasiou V, Mariolis A, Mihas C, et al. (2007) Impact of additional sampling in the TRUS-guided biopsy for the diagnosis of prostate cancer. Urol Int 78(4): 313-316.

6. Fleshner NE, O'Sullivan M, Fair WR (1997) Prevalence and predictors of a positive repeat transrectal ultrasound guided needle biopsy of the prostate. J Urol 158(2): 505-509.

7. Zhu H, Roehl KA, Antenor JA, Catalona WJ (2005) Biopsy of men with PSA level of 2.6 and $4.0 \mathrm{ng} / \mathrm{ml}$ associated with favorable pathologic features and PSA progression rate: a preliminary analysis. Urology 66(3): 547-551.

8. Richie JP, Catalona WJ, Ahmann FR, Hudson MA, Scardino PT, et al. (1993) Effect of patient age on early detection of prostate cancer with serum prostate-specific antigen and digital rectal examination. Urology 42(4): 365-369.

9. Svetec D, McCabe K, Peretsman S, Klein E, Levin H, et al. (1998) Prostate rebiopsy is a poor surrogate of treatment efficacy in localised prostate cancer. J Urol 159(5): 1606-1610.

10. Applewhite JC, Matagla BR, McCullough DL (2002) Results of the 5 region prostate biopsy method: the repeat biopsy population. J Urol 168(2): 500-505.

11. Presti JC Jr, O'Dowd GJ, Miller MC, Mattu R, Veltri RW (2003) Extended peripheral zone biopsy schemes increase cancer detection rates and minimize variance in prostate specific antigen and age related cancer rates: results of a community multi-practice study. J Urol 169(1): 125-130.

12. Catalona WJ, Hudson MA, Scardino PT, Richie JP, Ahmann FR, et al. (1994) Selection of optimal prostate specific antigen cutoffs for early detection of prostate cancer: receiver operating characteristic curves. J Urol 152(6.1): 2037-2041.

13. Catalona WJ, Smith DS, Ornstein DK (1997) Prostate cancer detection in men with serum PSA concentration of 2.6 to $4.0 \mathrm{ng} / \mathrm{ml}$ and benign prostate examination. Enhancement of specificity with free PSA measurements. JAMA 277(18): 1452-1455.

14. Jradi MA, Dridi M, Teyeb M, Mohamed MO, Khiary R, et al. (2010) The 20-core prostate biopsy as an initial strategy: impact on the detection of prostate cancer. Can Urol Assoc J 4(2): 100-104.

15. Levine MA, Ittman M, Melamed J, Lepor H (1998) Two consecutive ultrasound guided sextant biopsies of the prostate for the detection of prostate cancer. J Urol 1590(2): 451-471. 
16. Uzzo RG, Wei JT, Waldbaum RS, Perlmutter AP, Byrne JC, et al. (1995) The influence of prostate size on cancer detection. Urology 46 (6): 831- 834.

17. Stewart CS, Leibovich BC, Weaver AL, Lieber MM (2001) Prostate cancer diagnosis using saturation needle biopsy technique after previous negative sextant biopsies. J Urol 166(1): 86-91.

18. Chun FK, Epstein JI, Ficarra V, Freedland SJ, Montironi $\mathrm{R}$, et al. (2010) Optimizing performance and interpretation of prostate biopsy: a critical analysis of the literature. Eur Urol 58(6): 851-853.

19. Eskicorapci SY, Baydar DE, Akbal C, Sofikerim M, Günay $M$, et al. (2004) An extended 10-core transrectal ultrasonography guided prostate biopsy protocol improves the detection of prostate cancer. Eur Urol 45(4): 444-448. 